\title{
Barriers to early detection of cognitive impairment in the elderly despite the availability of simple cognitive screening tools and the pharmacist's role in early detection and referral
}

\begin{abstract}
Aim: The aim of this review is to identify suitable cognitive screening tool that can be used by the pharmacist during home medication review in addition to calculating the medications total anticholinergic burden.
\end{abstract}

Data sources: A search of literature was conducted using PubMed, Embase, and Medline and Google Scholar databases to identify relevant studies using the following keywords: 'cognitive impairment', 'cognitive impairment AND diagnosis', 'cognitive scales', 'dementia', 'delirium', 'pharmacist role', 'mini-mental state examination (MMSE)', 'the Rowland dementia assessment scale (RUDAS)', 'the Alzheimer's Disease Assessment ScaleCognition (ADAS-Cog)' and 'barriers and problems'. Only informational websites, clinical trials and review articles were included.

Results: The mini-mental state examination (MMSE), the Rowland Dementia Assessment Scale (RUDAS), the Alzheimer's disease Assessment Scale- Cognition (ADAS-Cog), Psychogeriatric Assessment Scale (PAS) and Kimberley Indigenous Cognitive Assessment (KICA-Cog) require specialists training. The anxiety and depression checklist (K10) and worried about your memory (WAYM) can be self-administered without prior training. Anticholinergic burden (ACB) scoring system can also be used to determine the total medications anticholinergic burden.

Conclusion: The anxiety and depression checklist (K10) and worried about your memory (WAYM) can be used by the pharmacist during medication reviews to early detect and refer the elderly for further medical care supported by the calculated score for the patient total medications anticholinergic burden. 


\section{Introduction}

Cognitive function is a concept of multidimensional domains which are associated with the performance of normal healthy brain, including psychomotor ability, concentration and attention, information processing speed, executive function, visuospatial skill, language, memory and learning. ${ }^{1}$ Cognitive impairment is the deterioration in the function of either one or a number of these domains. ${ }^{2}$ This may be in a form of a single specific impairment or a group of related impairments. ${ }^{2}$ Furthermore, cognitive impairment is inferred from an individual's behaviour rather than observed directly. Mild cognitive impairment (MCI), isolated memory impairment or incipient dementia is a brain function disorder which involves the evolution and onset of cognitive deficits beyond those anticipated based on the individuals' age and education, but these deficits are not significant enough to disturb the individuals' activities of daily living. ${ }^{3}$ Also, MCI has been described as a transitional state between standard cognitive function and Alzheimer's disease (AD). ${ }^{4}$

There has been a dramatic increase in the use of cognitive screening tests to provide detection tools and objective measures of cognitive functioning over the last 10 years. A substantial number of screening tests exist including the mini-mental state examination (MMSE), the Rowland Dementia Assessment Scale (RUDAS), the Alzheimer's disease Assessment Scale- Cognition (ADAS-Cog), Psychogeriatric Assessment Scale (PAS) and Kimberley Indigenous Cognitive Assessment (KICACog), Anxiety and depression checklist (K10) and worried about your memory (WAYM) (table 1). Due to the effect of some medications on cognition, the pharmacist is in a good position to use the Anticholinergic Cognitive Burden scale (ACB) to guide their advice to other health professionals who then can provide the required clinical interventions. ACB is used as a research tool to examine the use of anticholinergic medications in population with high risk such as demented patients. Based on medications anticholinergic properties, each medication is given a score of 1, 2 or 3 . Fox et al. (2011) allocated a score of either two or three is given to medications which definitely possess anticholinergic effects and a score of one is given to medications with potential anticholinergic effects. ${ }^{5}$ For each medication with definite anticholinergic effects Fox et al. (2011) concluded that a $46 \%$ increase in cognitive impairment risk may result over six years and that the rise in the total score 
of ACB by one point was linked with the increased risk of death by $26 \%$ and a reduction in MMSE score by 0.33 points over 2 years. $^{6}$

\section{Aim}

This review is a part of a parent study which aims to investigate the role of pharmacist, in early detection of medication that may compromise the elderly cognition, during home medication review, and early referral to treating doctor for further action whenever possible. The aim of this review is to identify suitable cognitive screening tool that can be used by the pharmacist during medication review in addition to calculating the medications total anticholinergic burden.

\section{Method}

In order to check the validity of current tools available to tests cognition and the possibility of pharmacists administering these tests, a search of literature was conducted using PubMed, Embase, Medline and Google Scholar databases to identify relevant studies using the following keywords: 'cognitive impairment', 'cognitive impairment AND diagnosis', 'cognitive scales', 'dementia', 'delirium', 'pharmacist role', 'mini-mental state examination (MMSE)', 'the Rowland dementia assessment scale (RUDAS)', 'the Alzheimer's Disease Assessment Scale- Cognition (ADAS-Cog)' and 'barriers and problems'.

Number of tools was identified as potential tools that can be used in primary care setting (table 1). Only informational websites, clinical trials and review articles were included. Those were directly related to the review and the parent study concept is listed in table 2 and 3.

\section{Literature Review}

The diagnosis of different cognitive impairments is challenging. Despite the presence of different diagnostic tools to distinguish between different cognitive impairments causes and levels, getting a correct diagnosis still considered as a significant challenge. ${ }^{7}$ For instance, delirium may be overlooked when mild, considered as part of normal aging, or incorrectly diagnosed as a psychiatric illness e.g. depression or dementia. Many studies showed that physician failed to recognise $32-67 \%$ of delirious 
patients. ${ }^{7,8}$ Additionally, other studies demonstrated that cognitive function is rarely formally assessed unless it is reported as an issue by the patient ${ }^{9}$ and there is frequently minimal knowledge about the course of any cognitive impairment or the baseline cognitive status of patients. ${ }^{10}$ Although delirium has the potential to be the sole manifestation of a serious illnesses such as myocardial infarction (MI) or sepsis, it is not usually considered as a significant clinical syndrome due to their acute nature and its multiple and varied aetiologies among the elderly which may present as atypical to the known disease presentation. ${ }^{10}$ Health professionals tend to pay attention when delirious patient present with inappropriate behaviours, hallucinations and agitation; whereas delirium associated with lethargy and decreased activity is commonly missed. ${ }^{10}$ One study found that $37 \%$ of 74 patients considered depressed by house staff consultees were actually re-diagnosed by the consulting psychiatrist and found to suffer from delirium. ${ }^{11}$ Furthermore, another study conducted by Tiamson, et al. (1993) showed that about $27 \%$ of 677 depressed patients were actually suffering of an organic mental disorder after they re-diagnosed by consulting psychiatrist. ${ }^{12}$ Another study demonstrated the low sensitivity of the diagnosis of delirium by emergency department doctors although the prevalence of delirium among elderly patients in this department is relatively high. ${ }^{13}$ Johnson et al. (1992) noted that delirium was explicitly recognised in only $5 \%$ of the studied elderly general hospital admissions. ${ }^{14}$ Also, the study showed that $25 \%$ of the missed cases were diagnosed as a functional psychiatric disorder while $25 \%$ of the cases were diagnosed as dementia and $50 \%$ of the cases were documented as no diagnosis. ${ }^{14}$ Patients with mild dementia can also suffer from delirium due to other underlying causes, which may early worsen their quality of life than if it is managed. ${ }^{15}$ Additionally, it has been shown that hypoactive delirium, which accounts for $25 \%$ of cases, is most likely to be missed as it is mistakenly diagnosed as depression and/or its symptoms don't disturb other people. ${ }^{16}$ One study, which was conducted in two geriatric hospitals, showed that the diagnosis of different cognitive impairments among hospitalized older patients was insufficient. ${ }^{17}$ The cognitive impairment was recorded in medical notes in $79.5 \%$ of the cases and the cognitive testing was conducted on only $47.7 \%$ of patients with diagnosed dementia. ${ }^{17}$ The detection of dementia was recorded in 47/88 of dementia patients. Eight of these patients had been found to have a false-positive diagnosis. Furthermore, delirium was recorded in only 31 out of 77 delirious patients, who were diagnosed by 
the researchers. ${ }^{17}$ Furthermore, poor documentation and detection of underlying causes may result in under-or over- treatment ${ }^{17}$ as explicit identification of cognitive impairment such as delirium has been correlated with better outcomes in term of lower mortality and shorter in-patient hospital stays. ${ }^{18}$ Missing ACB as the cause, especially during the short encounter with patients in primary care setting may affect patients' management in many sphere including patients' medications. Pharmacist spend at the least 60 minutes with patients during the HMR process, if pharmacists can then include a validated cognition tests tools and calculate the ACB to include their results in the findings report, this may provide the treating doctor with valuable information and possible early intervention to improve patients quality of life. However, this hypothesis is yet to be tested in the parent study of this review, which the author is currently undertaking.

\subsection{Medications related issues}

Medication-related cognitive impairments arising from poor medication management can result in significant morbidity and secondary care admissions. ${ }^{19}$ It has been demonstrated that medications contribute to about $40 \%$ of cases of delirium. ${ }^{20}$ Furthermore, medication errors and adverse drug events including those that are related to cognition may result in admission to intensive care units. ${ }^{21}$ One study showed that $6.5 \%$ of all admissions to secondary care units are caused by adverse drug reactions. ${ }^{19}$ Also, the study found that each year 6000 deaths are associated with such events in England. ${ }^{19}$ Another study, which considered impaired cognition as the essential predictor of avoidable medication-related admissions to hospitals, showed that $5.6 \%$ of unplanned admissions were linked to medications and almost half $(46.5 \%)$ of them were potentially avoidable. ${ }^{22}$ It has been shown that dementia people are often prescribed medications which impair and/or worsen their cognitions such as medications with sedative and/or anticholinergic activities. ${ }^{23,}{ }^{24}$ Approximately $20-50 \%$ of dementia patients have been shown to take at least one medication with anticholinergic properties. ${ }^{21}$ Moreover, dementia patients may fail to identify potential medications errors as they less likely to appreciate adverse reaction, ask about their prescriptions or any change in their drugs and know whether they need monitoring. ${ }^{25,26}$ Thus, a complete medication review should be considered to improve cognitive

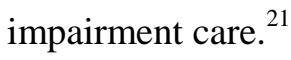




\section{Pharmacist role in early detection of cognitive impairment}

Pharmacists can play an active role in early recognition and prevention of medication-induced cognitive impairment when consider that the ACB is actually a medications adverse effects, i.e. their prevention is an integrated activity to the pharmacy profession. It has been shown that pharmacists were able to decrease the rate of preventable adverse drug reaction after discharge from hospital through patient counselling, telephone follow up and medication review. ${ }^{27}$ Additionally, collaboration between pharmacists and doctors to investigate treatment, patient management and pharmacotherapy has been used in different countries to improve prescribing and disseminate new guidelines and knowledge. ${ }^{28}$ One study $(2001)^{28}$ with elderly subjects showed that the use of antidepressants with highly anticholinergic activities reduced and those with less anticholinergic properties increased through continuing medical education conducted by pharmacists and doctors. ${ }^{28}$ Moreover, it has been demonstrated that the educational program resulted in a significant reduction in the use of antipsychotic medication, which also exhibits anticholinergic properties, with no rise in the prevalence of behavioural problems. ${ }^{29}$ This may result in less anticholinergic burden including medication-induced cognitive impairment. Furthermore, He and Ball showed in their theoretical study that the reduction in anticholinergic burden (ACB) score by one can be achieved in $85 \%$ of the cases with score of 3 and $59 \%$ of the cases with score of 1 by altering the medication regimen based on appropriate practice guidelines. ${ }^{30}$ The Aging Brain Program at Indiana University also developed a guideline which is composed of a list of medications that can be used as alternatives to the medications with definite anticholinergic activities. The use of this guideline may help health professionals to provide care for individuals who suffer from cognitive impairment including delirium, mild cognitive impairment or dementia.. ${ }^{31}$ Another study with elderly frail subjects showed that the anticholinergic drug scale (ADS) score reduced significantly after pharmacist-initiated medication changes. ${ }^{32}$ However, the same study found that medication changes did not reduce the dryness of the mouth or the serum anticholinergic activity (SAA) significantly. ${ }^{32}$

Table 1 lists the commonly used assessment tools. As pharmacists do not undertake training in cognitive assessment as core skill in their undergraduate program, but their role as member of the 
primary care team is within the pharmacist scope of practice, most assessment tools, but not K10 or WAYM, are not feasible to be used unless further training is completed post-graduation to be able to produce consistent interpretation of the results.

\section{Conclusion}

A substantial number of screening tests exist including MMSE, RUDAS, ADAS-Cog, PAS, KICACog, K10 and WAYM.

One of the pharmacist core professional activities is to reduce medications adverse effects. ACB, when it is not the main indication of the medications prescribed to the patients is considered as side effects. Accordingly calculating the total score of the ACB caused by the patient medication theoretically can be used to guide reduction and management of medications to improve patients' quality of life. However, the same score may not produce the same effect in all patients, accordingly a supporting tool the early detect the effect of the score on the patient cognitive functioning is important. The pharmacist has this opportunity to spend 60 minutes with the patient during home medication review, it is hypothesis that if the pharmacist calculated the ACB total score and administered the K10 and WAYM and provide those results to the treating doctor as part of the HMR report, it may guide the doctor management of the patient medication or trigger a referral of the patient for further investigations leading to better health outcomes and quality of life. However further research is required to prove this hypothesis to be actual or null.

\section{Reference}


1. Jansen C, Miaskowski C, Dodd M, Dowling G, Kramer J. Potential mechanisms for chemotherapy-induced impairments in cognitive function. Oncol Nurs Forum 2005; 32(6): 1151-63.

2. Gyurak A, Goodkind MS, Madan A, Kramer JH, Miller BL, Levenson RW. Do tests of executive functioning predict ability to down-regulate emotions spontaneously and when instructed to suppress? Cogn Affect Behav Neurosci 2009; 9(2): 144-52.

3. Petersen RC, Smith GE, Waring SC, Ivnik RJ, Tangalos EG, Kokmen E. Mild cognitive impairment: clinical characterization and outcome. Arch Neurol 1999; 56(3): 303-8.

4. Winblad B, Palmer K, Kivipelto M, Jelic V, Fratiglioni L, Wahlund LO, et al. Mild cognitive impairment - beyond controversies, towards a consensus: report of the International Working Group on Mild Cognitive Impairment. J Intern Med 2004; 256(3): 240-6.

5. Campbell NL, Boustani MA, Lane KA, Gao S, Hendrie H, Khan BA, et al. Use of anticholinergics and the risk of cognitive impairment in an African American population. Neurology 2010; 75(2): 152-9.

6. Fox C, Richardson K, Maidment ID, Savva GM, Matthews FE, Smithard D, et al. Anticholinergic medication use and cognitive impairment in the older population: the medical research council cognitive function and ageing study. J Am Geriatr Soc 2011; 59(8): 1477-83.

7. Gustafson Y, Brannstrom B, Norberg A, Bucht G, Winblad B. Underdiagnosis and poor documentation of acute confusional states in elderly hip fracture patients. J Am Geriatr Soc 1991; 39(8): 760-5.

8. Francis JSS, Martin D, Kapoor W. Delirium in elderly general medical patients: common but often unrecognised. Clin Res 1988; 36(711A).

9. vonAmmon Cavanaugh $\mathrm{S}$. The prevalence of emotional and cognitive dysfunction in a general medical population: using the MMSE, GHQ, and BDI. Gen Hosp Psychiatry 1983; 5(1): 15-24.

10. Inouye SK. The dilemma of delirium: clinical and research controversies regarding diagnosis and evaluation of delirium in hospitalized elderly medical patients. Am J Med 1994; 97(3): 278-88.

11. Margolis RL. Nonpsychiatrist house staff frequently misdiagnose psychiatric disorders in general hospital inpatients. Psychosomatics 1994; 35(5): 485-91.

12. Armstrong SC, Cozza KL, Watanabe KS. The misdiagnosis of delirium. Psychosomatics 1997; 38(5): 433-9.

13. Michel E, Rousseau F, Cole M, Primeau F, et al. Prevalence and detection of delirium in elderly emergency department patients. Can Med Assoc J 2000; 163(8): 977-81.

14. Johnson JC, Kerse NM, Gottlieb G, Wanich C, Sullivan E, Chen K. Prospective versus retrospective methods of identifying patients with delirium. J Am Geriatr Soc 1992; 40(4): 316-9.

15. Inouye SK. Delirium in older persons. N Engl J Med 2006 ; 354(11): 1157-65.

16. Bales JW, Wagner AK, Kline AE, Dixon CE. Persistent cognitive dysfunction after traumatic brain injury: A dopamine hypothesis. Neurosci Biobehav Rev 2009; 33(7): 981-1003. 
17. Laurila JV, Pitkala KH, Strandberg TE, Tilvis RS. Detection and documentation of dementia and delirium in acute geriatric wards. Gen Hosp Psychiatry 2004; 26(1): 31-5.

18. Rockwood K, Cosway S, Stolee P, Kydd D, Carver D, Jarrett P, et al. Increasing the recognition of delirium in elderly patients. J Am Geriatr Soc 1994; 42(3): 252-6.

19. Pirmohamed M, James S, Meakin S, Green C, Scott AK, Walley TJ, et al. Adverse drug reactions as cause of admission to hospital: prospective analysis of 18820 patients. BMJ $2004 ; 329$ (7456): 15-9.

20. Flacker JM, Marcantonio ER. Delirium in the elderly. Optimal management. Drugs Aging 1998; 13(2): 119-30.

21. Maidment ID, Fox C, Boustani M, Katona C. Medication management - the missing link in dementia interventions. Int J Geriatr Psychiatry 2012; 27(5): 439-42.

22. Leendertse AJ, Egberts AC, Stoker LJ, van den Bemt PM. Frequency of and risk factors for preventable medication-related hospital admissions in the Netherlands. Arch Intern Med 2008; 168(17): 1890-6.

23. Mulsant BH, Pollock BG, Kirshner M, Shen C, Dodge H, Ganguli M. Serum anticholinergic activity in a community-based sample of older adults: relationship with cognitive performance. Arch Gen Psychiatry 2003; 60(2): 198-203.

24. Starr JM, Whalley LJ. Drug-induced dementia. Incidence, management and prevention. Drug Saf 1994; 11(5): 310-7.

25. Maidment ID, Lelliott $P$, Paton C. Medication errors in mental healthcare: a systematic review. Qual Saf Health Care 2006; 15(6): 409-13.

26. Barber ND, Alldred DP, Raynor DK, Dickinson R, Garfield S, Jesson B, et al. Care homes' use of medicines study: prevalence, causes and potential harm of medication errors in care homes for older people. Qual Saf Health Care 2009; 18(5): 341-6.

27. Schnipper JL, Kirwin JL, Cotugno MC, Wahlstrom SA, Brown BA, Tarvin E, et al. Role of pharmacist counseling in preventing adverse drug events after hospitalization. Arch Intern Med 2006; 166(5): 565-71.

28. Eijk MECv, Avorn J, Porsius AJ, Boer Ad. Reducing prescribing of highly anticholinergic antidepressants for elderly people: randomised trial of group versus individual academic detailing. BMJ 2001; 322(7287): 654.

29. Ray Wa TJAMKG, et al. Reducing antipsychotic drug use in nursing homes: A controlled trial of provider education. Arch Intern Med 1993; 53(6): 713-21.

30. He Z, Ball PA. Can medication management review reduce anticholinergic burden $(\mathrm{ACB})$ in the elderly? Encouraging results from a theoretical model. Int Psychogeriatr 2013; 25(09): 1425-31.

31. Anticholinergic Cognitive Burden Scale: Aging Brain Program of the Indiana University Center for Aging Research; 2012. [cited 2016 3rd February]. Available from: http://www.agingbraincare.org/uploads/products/ACB_scale_-_legal_size.pdf.

32. Kersten H, Molden E, Tolo IK, Skovlund E, Engedal K, Wyller TB. Cognitive effects of reducing anticholinergic drug burden in a frail elderly population: a randomized controlled trial. J Gerontol A Biol Sci Med Sci 2013; 68(3): 271-8.

33. Tombaugh TN, McIntyre NJ. The mini-mental state examination: a comprehensive review. J Am Geriatr Soc 1992; 40(9): 922-35. 
34. Shigemori K, Ohgi S, Okuyama E, Shimura T, Schneider E. The factorial structure of the Mini-Mental State Examination (MMSE) in Japanese dementia patients. BMC Geriatr 2010; 10: 36.

35. Storey JE, Rowland JTJ, Conforti DA, Dickson HG. The Rowland Universal Dementia Assessment Scale (RUDAS): a multicultural cognitive assessment scale. Int Psychogeriatr 2004; 16(01): 13-31.

36. Chu LW, Chiu KC, Hui SL, Yu GK, Tsui WJ, Lee PW. The reliability and validity of the Alzheimer's Disease Assessment Scale Cognitive Subscale (ADAS-Cog) among the elderly Chinese in Hong Kong. Ann Acad Med Singapore 2000; 29(4): 474-85.

37. Kolibas E, Korinkova V, Novotny V, Vajdickova K, Hunakova D. ADAS-cog (Alzheimer's Disease Assessment Scale-cognitive subscale)--validation of the Slovak version. Bratisl Lek Listy 2000; 101(11): 598-602.

38. Jorm AF, Mackinnon AJ, Christensen H, Henderson AS, Jacomb PA, Korten AE. The psychogeriatric assessment scales (PAS): further data on psychometric properties and validity from a longitudinal study of the elderly. Int J Geriatr Psychiatry 1997; 12(1): 93100.

39. Jorm AF, Mackinnon AJ, Henderson AS, Scott R, Christensen H, Korten AE, et al. The Psychogeriatric Assessment Scales: a multi-dimensional alternative to categorical diagnoses of dementia and depression in the elderly. Psychol Med 1995; 25(3): 447-60.

40. LoGiudice D, Smith K, Thomas J, Lautenschlager NT, Almeida OP, Atkinson D, et al. Kimberley Indigenous Cognitive Assessment tool (KICA): development of a cognitive assessment tool for older indigenous Australians. Int Psychogeriatr 2006; 18(2): 269-80.

41. A Guide to the K10 Symptom Scale 2005 [cited 2016 15th January]. Available from: www.mhima.org.au/_literature 73655/K10.

42. Kessler RC, Andrews G, Colpe LJ, Hiripi E, Mroczek DK, Normand SL, et al. Short screening scales to monitor population prevalences and trends in non-specific psychological distress. Psychol Med 2002; 32(6): 959-76.

43. Andrews G, Slade T. Interpreting scores on the Kessler Psychological Distress Scale (K10). Aust N Z J Public Health 2001; 25(6): 494-7.

44. Worried about your memory? 2013 [cited 2015 14th December]. Available from: https://fightdementia.org.au/sites/default/files/2013_WAYM-DL_6pp.pdf. 
Table 1 - Summary of common assessment tools used for clinical diagnosis of Cognitive Function

\begin{tabular}{|c|c|}
\hline Tool & comments \\
\hline MMSE & $\begin{array}{l}\text { MMSE is a screening tool that provides a brief, objective measure of cognitive function. }{ }^{33,34} \\
\text { MMSE scores are useful in documenting cognitive change serially and in estimating the severity of } \\
\text { cognitive impairment quantitatively. }{ }^{33,}{ }^{34} \text { Despite the wide range of cognitive screening tests } \\
\text { available, MMSE is the most widely used and popular clinical measure due to its availability in } \\
\text { many languages. }{ }^{33} \text { The MMSE is used widely in studies and community surveys. }{ }^{33} \text { It forms part of } \\
\text { the diagnostic interview schedule and a structured interview used recently in a large five-site } \\
\text { epidemiological catchment area study promoted by the National Institute of Mental Health. }{ }^{34}, 34 \\
\text { Additionally, MMSE has been incorporated into several standardised interviews designed to help } \\
\text { diagnose dementia and to assess cognitive impairment. }{ }^{33,34} \text { The National Institute of Neurological } \\
\text { and Communicative Disorders and Stroke and the Alzheimer's disease and Related Disorders } \\
\text { Association has recommended MMSE as one of the tests to document the clinical diagnosis of } \\
\text { possible Alzheimer's disease. }{ }^{33} \text { The MMSE has a maximum score of } 30 \text { points and consists of a } \\
\text { range of questions which can be administered ordinarily in } 5-10 \text { minutes. }{ }^{33} \text {, } 34 \text { The questions are } \\
\text { categorised into seven groups, each representing a different cognitive function domain. They are } \\
\text { orientation to time ( } 5 \text { points), orientation to place (5 points), attention and calculation (5 points), } \\
\text { registration of three words ( } 3 \text { points), recall of three words ( } 3 \text { points), language ( } 8 \text { points) and } \\
\text { visual construction ( } 1 \text { point). }{ }^{33} \text { Although MMSE has been shown to fulfil its original goal of } \\
\text { providing a brief screening test that quantitatively assesses the severity of cognitive impairment } \\
\text { and documents cognitive changes occurring over time, it should not, by itself, be used as a } \\
\text { diagnostic tool to identify dementia. }{ }^{33}\end{array}$ \\
\hline RUDAS & $\begin{array}{l}\text { RUDAS is a multicultural cognitive assessment scale. }{ }^{35} \text { It is short cognitive screening instrument } \\
\text { designed to minimise the effects of cultural learning and language diversity on the assessment of } \\
\text { baseline cognitive performance. }{ }^{35} \text { When administering the RUDAS, it is important that the } \\
\text { respondent is encouraged to communicate in the language with which they are most competent } \\
\text { and comfortable. }{ }^{35} \text { Also, the test taker should be as relaxed as possible, because test anxiety can } \\
\text { interfere with performance on cognitive tests }{ }^{35} \text {. Additionally, the RUDAS test is conducted in a } \\
\text { quiet area, so the test taker can hear clearly. }{ }^{35} \text { It is significant to identify at the start of the } \\
\text { assessment, if the test taker has hearing problems and accommodate for this as much as possible } \\
\text { such as speaking slowly and clearly and encouraging test takers to wear any hearing aids } \\
\text { necessary. }{ }^{35} \text { Furthermore, RUDAS provides a large print version of the test if the test taker suffers } \\
\text { severe hearing impairment. }{ }^{35} \text { RUDAS also ensures that the test taker is using reading glasses when } \\
\text { necessary and that there is sufficient light in the room. }{ }^{35} \text { At the end of the RUDAS test, the scores } \\
\text { will be added up for each item to obtain a total score out of } 30 .{ }^{35} \text { Test takers with scores of } 22 \text { or } \\
\text { less will be concluded to possibly have cognitive impairment, and will be referred on for further } \\
\text { investigation by the relevant physician. }{ }^{35} \text { If test takers suffer a physical disability (e.g. vision, } \\
\text { hearing, hemiparesis, amputee, stroke, aphasia) which may affect their ability to perform certain } \\
\text { items on the RUDAS, it is important to interpret any total score less than } 22 \text { with caution. }{ }^{35} \text { Thus, } \\
\text { further research is necessary to assess validity of the RUDAS in this sub-group of patients. }{ }^{35}\end{array}$ \\
\hline
\end{tabular}




\begin{tabular}{|c|c|}
\hline $\begin{array}{l}\text { ADAS- } \\
\text { Cog }\end{array}$ & $\begin{array}{l}\text { It has been reported that ADAS-cog is the most popular cognitive testing instrument used in } \\
\text { clinical trials and a sensitive cognitive function assessment scale for Alzheimer's Disease (AD). }{ }^{36} \text { Its } \\
\text { validity and reliability have been established in the original English version. }{ }^{36} \text { ADAS-cog consists of } \\
\text { eleven items which are designed to measure the severity of the most important and the core } \\
\text { symptoms of (AD) including orientation, memory, praxis function and language disturbances. }{ }^{37} \\
\text { ADAS-cog is not designed for use as a diagnostic tool, but scores on the scale discriminate patients } \\
\text { with clinically diagnosed AD from non-dementia subjects. }{ }^{36} \text { Its sensitivity to detect change has } \\
\text { been documented by longitudinal follow-up data. }{ }^{36} \text { On average, AD patients show an increase in } \\
\text { ADAS-cog scores of about } 7 \text { to } 8 \text { points per year interval. }{ }^{36} \text { It has been reported that ADAS-cog is } \\
\text { more sensitive than other dementia rating scales like Folstein MMSE. }{ }^{36} \text { Thus, ADAS-cog is } \\
\text { commonly employed as a primary outcome measure to assess the effects of cognitive enhancing } \\
\text { drugs in clinical trials of new drug treatment for AD. }{ }^{36}\end{array}$ \\
\hline PAS & $\begin{array}{l}\text { The PAS is designed to gather information on the main psychogeriatric disorders: depression and } \\
\text { dementia. }{ }^{38,} 39 \text { PAS differs from conventional approaches to psychogeriatric assessment in a } \\
\text { number of significant ways. }{ }^{38} \text { Psychogeriatric assessment is generally the province of people with } \\
\text { extensive specialist training in geriatrics or psychiatry. }{ }^{38} \text { PAS aims to assist a wider range of people } \\
\text { to carry out psychogeriatric assessment, so it provides a straightforward method of gathering and } \\
\text { interpreting the relevant information without the necessity for prolonged training. }{ }^{38,}, 39 \\
\text { Furthermore, in conventional thinking, people having depression or dementia are in a distinct } \\
\text { group from 'normal' people. }{ }^{38} \text { It is true that when people with psychogeriatric disorders are seen } \\
\text { by health care workers they appear to be categorically apparent from other people. }{ }^{38} \text { However, } \\
\text { when the whole elderly population is looked at, depression and dementia are seen as part of a } \\
\text { continuum. }{ }^{38,} \text {, }{ }^{39} \text { For instance, there is a continuum ranging from successful cognitive ageing at one } \\
\text { end to severe dementia at the other. }{ }^{38} \text { There is a different continuum ranging from positive well- } \\
\text { being in old age to severe depression. }{ }^{38} \text { However, the PAS aims to put people along a number of } \\
\text { appropriate continua and helps by collecting information in a systematic way. }{ }^{38} \text { The PAS also gives } \\
\text { guidance on how this information should be interpreted by comparing the results to the normal } \\
\text { range found in the society. } .^{38} \text { Thus, PAS assesses psychogeriatric disorders on scales rather than as } \\
\text { categories. Given that PAS provides a method of assessing psychogeriatric disorders, it does not } \\
\text { tell the user what action to take if problems are found, so the use of the information in PAS is only } \\
\text { to guide care decisions which should be based on the user's professional expertise. }{ }^{38,39}\end{array}$ \\
\hline $\begin{array}{l}\text { KICA- } \\
\text { Cog }\end{array}$ & $\begin{array}{l}\text { The KICA was developed in response to the need for a validated cognitive screening tool for older } \\
\text { Indigenous Australians living in rural and remote areas. }{ }^{40} \text { The KICA-Cog section is validated with } \\
\text { Indigenous Australians aged } 45 \text { years and above from the Kimberley and Northern Territory. }{ }^{40} \text { The } \\
\text { KICA-cog has a maximum score of } 39 \text {. A score of } 33 / 39 \text { and below indicates possible dementia. }{ }^{40} \\
\text { Those with a low KICA-Cog score should be referred to a doctor for medical screens to rule out } \\
\text { other causes of cognitive impairment, some of which are reversible, or to confirm dementia. }{ }^{40} \\
\text { KICA-Cog's cognitive assessment contains the informant (carer) report. which has been validated } \\
\text { with a score of } 3 / 16 \text { or above indicating that further investigations are required. }{ }^{40} \text { Other sections } \\
\text { of the KICA tool are for information gathering to assist in determining subtypes, severity, } \\
\text { differential diagnoses and management. }{ }^{40} \text { As language skills are assessed in the cognitive section it } \\
\text { is recommended that an interpreter be used when required. }{ }^{40} \text { Furthermore, KICA-cog contains a } \\
\text { visual naming task. }{ }^{40} \text { If an individual is unable to name a certain photo (crocodile or emu) because } \\
\text { of their own cultural reasons it can be replaced by the dog or horse pictures. }{ }^{40} \text { Thus, KICA-Cog } \\
\text { appears to be a reliable assessment tool in an Australian older ordinarily living indigenous } \\
\text { population for cognitive impairment. }\end{array}$ \\
\hline K10 & $\begin{array}{l}\text { The K10 is a simple widely recommended tool to measure of psychological distress as well as the } \\
\text { outcomes after different mental health problems as the K10 is available to the public through the } \\
\text { website of Clinical Research Unit for Anxiety and Depression to identify who requires treatment as } \\
\text { anyone can administer it. }{ }^{4,42} \text { There are five responses in the ten item scale. Score one being none } \\
\text { of the time and five all of the time. Thus, total scores ranges from } 10 \text { which means no distress to } 50 \\
\text { which means sever distress. }{ }^{42} \text { Composite International Diagnostic Interview (CIDI) identifies } \\
\text { people with a score falls in between 0-15 to have the risk of one quarter of the population of }\end{array}$ \\
\hline
\end{tabular}




\begin{tabular}{|c|c|}
\hline & $\begin{array}{l}\text { meeting the depressive or anxiety disorder criteria. }{ }^{41,43} \text { People with a score falls in between } 16-30 \\
\text { have } 25 \% \text { chance of developing a current depressive or anxiety disorder and chance of } 1 \% \text { of ever } \\
\text { attempting a suicide in their life. }{ }^{41,43} \text { People with a score falls in between } 30-50 \text { have } 75 \% \text { chance } \\
\text { of meeting the criteria for a depressive or anxiety disorder and a chance of } 6 \% \text { of ever attempting a } \\
\text { suicide in their lives. }{ }^{41}\end{array}$ \\
\hline WAYM & $\begin{array}{l}\text { The Worried about your memory (WAYM) is a tool developed by Alzheimer's Australia and aims } \\
\text { to increase awareness of the early symptoms and signs of dementia. WAYM encourages people to } \\
\text { seek help if they have memory concerns. }{ }^{44} \text { WAYM contains } 12 \text { statements which the person should } \\
\text { comments on them by choosing either rarely, sometimes or often. If a person has ticked } \\
\text { 'sometimes' or 'often' it is recommended that he /she see his/her doctor. }{ }^{44}\end{array}$ \\
\hline
\end{tabular}


Table 2 - Literature Selection by contribution to Research Concept

\begin{tabular}{|c|c|c|l|}
\hline $\begin{array}{c}\text { Primary author } \\
\text { \& reference } \\
\text { [n(total) = 44] }\end{array}$ & Impact & Citations & Contribution to the research concept \\
\hline Gyurak A. (2) & 3.287 & 80 & Definition of cognitive impairment. . \\
\hline Gustafson Y. (7) & 4.572 & 218 & $\begin{array}{l}\text { Cognitive impairment is misdiagnosed by health care } \\
\text { professionals. }\end{array}$ \\
\hline $\begin{array}{c}\text { vonAmmon } \\
\text { Cavanaugh S. (9) }\end{array}$ & 2.606 & 202 & Cognitive function is rarely formally assessed. \\
\hline $\begin{array}{c}\text { Inouye SK.(10) } \\
\text { Michel E. (13) }\end{array}$ & 5.003 & 611 & Problem associated with cognitive impairment \\
\hline Inouye SK. (15) & 55.873 & 1418 & Mild dementia and delirium. \\
\hline $\begin{array}{c}\text { Laurila JV. (17) } \\
\text { Maidment ID. } \\
\text { (21) }\end{array}$ & 2.606 & 97 & $\begin{array}{l}\text { different cognitive impairments misdiagnosed in } \\
\text { hospital. }\end{array}$ \\
\hline $\begin{array}{c}\text { Marim } \\
\text { Mulsant BH. (23) }\end{array}$ & 14.48 & 249 & $\begin{array}{l}\text { Medication errors and adverse drug events related to } \\
\text { cognition and hospital admission. }\end{array}$ \\
\hline $\begin{array}{c}\text { He Z. (30) } \\
\text { Medications prescribing for demented people. }\end{array}$ \\
\hline
\end{tabular}


Table 3 - Search example using Medline data base

\begin{tabular}{|l|c|c|c|}
\hline \multicolumn{1}{|c|}{ Search terms } & First search: abstracts & $\begin{array}{l}\text { Second filter: English } \\
\text { language, Journal, } \\
\text { elderly (65+years old) }\end{array}$ & $\begin{array}{l}\text { Third filter: Full } \\
\text { text papers }\end{array}$ \\
\hline Cognitive impairment & 45,920 & 17,135 & 4,927 \\
\hline $\begin{array}{l}\text { Cognitive impairment } \\
\text { AND diagnosis }\end{array}$ & 15,305 & 7,702 & 2,155 \\
\hline Cognitive scales & 4,383 & 1,772 & 561 \\
\hline Dementia & 95,025 & 40,169 & 10,498 \\
\hline Delirium & 12,850 & 3,656 & 949 \\
\hline Pharmacist role & 2,641 & 301 & 1,084 \\
\hline $\begin{array}{l}\text { Mini-mental state } \\
\text { examination (MMSE) }\end{array}$ & 4,786 & 3,315 & 6 \\
\hline $\begin{array}{l}\text { the Rowland dementia } \\
\text { assessment scale } \\
\text { (RUDAS) }\end{array}$ & 19 & 36 & 12 \\
\hline $\begin{array}{l}\text { the Alzheimer's Disease } \\
\text { Assessment Scale- } \\
\text { Cognition (ADAS-Cog) }\end{array}$ & 49 & 3,089 & 1,149 \\
\hline $\begin{array}{l}\text { Barriers and problems } \\
\text { cognitive impairment } \\
\text { diagnosis }\end{array}$ & 15,816 & & \\
\hline $\begin{array}{l}\text { Cognitive impairment } \\
\text { Cognitive impairment } \\
\text { AND diagnosis } \\
\text { Cognitive Scales } \\
\text { Dementia Delirium } \\
\text { Pharmacist role }\end{array}$ & 6,676 & & \\
\hline
\end{tabular}

